\title{
Seasonality in Faecal Contamination of Drinking Water Sources in the Jirapa and Kassena-Nankana Municipalities of Ghana
}

Alfred Dongzagla ${ }^{\mathrm{a},}$, Sarah Jewitt ${ }^{\mathrm{b}}$, Sarah O’Hara ${ }^{\mathrm{b}}$

a. Department of Planning, Faculty of Planning and Land Management, University for Development Studies, Tamale, Ghana.Email: adongzagla@yahoo.com

b. School of Geography, University of Nottingham, NG7 2RD, Nottingham, United

Kingdom.Email:sarah.jewitt@nottingham.ac.uk,sarah.o'hara@nottingham.ac.uk

* Corresponding author

\begin{abstract}
This paper examines seasonal variations in faecal contamination of drinking water sources in the Jirapa and Kassena-Nankana Municipalities of Ghana. Data collection involved a survey of 568 households, testing of faecal coliform concentrations in drinking water source samples (141 in the rainy season, 128 in the dry season), in-depth interviews with key water stakeholders, and field observation to identify sources of faecal contamination. From the water quality testing, faecal coliforms were detected in all source types, including 'treated' pipeborne water. Contamination was significantly higher in the rainy season than in the dry season $(\mathrm{P}<0.05)$ with $51.8 \%$ of water samples in the rainy season and $27.3 \%$ in the dry season failing to meet the World Health Organisation and Ghana Standard Authority guideline on faecal coliform concentrations in drinking water sources. The proportion of population at risk of faecal contamination in the rainy season was $41.5 \%$ compared to $33.1 \%$ in the dry season. We argue that in Ghana and Sub-Saharan Africa at large, water surveillance agencies risk underestimating population exposed to faecal contamination through drinking water sources if monitoring is only done in the dry season. To avoid this, we recommend seasonal monitoring of faecal concentration in drinking water sources. However, in periods of limited resources, monitoring is most appropriate in the rainy season when the risk of contamination is high.
\end{abstract}


Keywords: Drinking water; faecal contamination; faecal coliform; 3M Petrifilm; season; Ghana

\section{Introduction}

Faecal contamination of drinking water is a major threat to public health, especially in developing countries. It is reported to cause diarrhoea, cholera, dysentery, typhoid, and polio (World Health Organisation [WHO], 2019; Odagiri et al., 2016). For instance, Odagiri et al. (2016) established a significant association between the levels of faecal contamination of household drinking water and the incidence of diarrhoea among children. Contaminated drinking water is estimated to cause 485,000 diarrhoeal deaths each year (WHO, 2019). To prevent waterborne diseases and deaths arising from faecal contamination, the WHO in its $4^{\text {th }}$ edition of water quality guidelines recommends that drinking water sources must be free from E. coli or faecal coliforms ${ }^{1}$ (WHO, 2011). This guideline provided by the WHO has been adopted by the Ghana Standard Authority (GSA) as a standard in Ghana (GSA, 2019).

Globally, 1.8 billion people (28\%) are at risk of faecal contamination through drinking water sources (Bain et al., 2014; Onda et al., 2012). Disparities, however, exist across space. Rural populations (41\%) are at a higher risk of exposure than urban populations (12\%) (Bain et al., 2014). Also, exposure to faecal contamination is more pronounced in developing countries, especially Africa (53\%) and South-East Asia (35\%) (Bain et al., 2014). It is more disturbing to note that $67 \%$ of the population using improved ${ }^{2}$ water sources in developing countries are at risk of health problems resulting from faecal contamination of drinking water

\footnotetext{
${ }^{1}$ Also known as Thermotolerant Coliform (TTC)

${ }^{2}$ The term improved water sources refers to water sources, which by the nature of their construction are protected from outside contamination, especially faecal coliforms (WHO/UNICEF Joint Monitoring Programme, 2015). They include pipe borne water, public tap/stand pipe, tube well/borehole, protected well, protected spring, rainwater and bottled water (WHO/UNICEF Joint Monitoring Programme, 2006).
} 
(United Nations Children's Fund [UNICEF] and WHO, 2019). As is the case for many Low and Middle-Income Countries (LMIC), current statistics on the proportion of population at risk of faecal contamination through drinking water sources in Ghana are unavailable. Available statistics, which date as far back as 2012 showed that 43\% of drinking water sources were contaminated with faeces (UNICEF and WHO, 2019).

Faecal contamination has been documented in all types of water sources (e.g. Bain et al., 2014; Boateng et al., 2013; Kostyla et al., 2015; Mkwate et al., 2016; WHO/UNICEF Joint Monitoring Programme, 2015; Ghana Statistical Service [GSS] et al., 2015). The level of faecal concentration in drinking water varies by source type with unimproved water sources generally having a higher risk of contamination compared to improved water sources (GSS et al., 2015). Also, among improved water sources, the risk of contamination of non-piped water sources is higher than for piped water systems and packaged water (Agensi et al., 2019; GSS et al., 2015; Smiley, 2017; Kirby et al., 2016; Kumpel et al., 2016). For instance, analysis of Total Coliform (TC) concentrations in drinking water sources in Kisoro District in Uganda by Agensi et al. (2019) revealed $100 \%$ contamination of all pond and river samples, $8.3 \%$ contamination of spring samples and no contamination for tap water. Factors linked to faecal contamination of drinking water sources include open disposal of solid waste (Kirby et al., 2016), open defecation by humans and animals (Mkwate et al., 2016; Schriewer, 2015), nearness of water sources to unsanitary latrines (Escamilla et al., 2013; Mkwate et al., 2016), rainfall (Kirby et al., 2016), location of water sources in low elevation areas (Kirby et al., 2016), leaking of pipes (Grady et al., 2014) and intermittent water supply (WHO, 2011). Aside from contamination at source, water is also at risk of contamination during transportation and in homes if not well handled or stored (Clasen and Bastable, 2003; Lavanya and Ravichandran, 2013; Agensi et al., 2019). 
In an effort to reduce waterborne diseases, Sustainable Development Goal (SDG) target 6.1 seeks to achieve universal and equitable access to safe and affordable drinking water for all by 2030 (United Nations [UN], 2015), with the indicator being the proportion of population using safely managed drinking water (UNICEF and WHO, 2018). By definition, 'safely managed water' implies drinking water from an improved water source that is located on premises, available when needed and free from faecal and priority chemical contamination (UNICEF and WHO, 2018). In view of this, regular monitoring of faecal contamination in drinking water sources is key in tracking progress towards SDG target 6.1 and also in makingdecisions on safe water supply. However, financial constraints often limit frequent monitoring in LMIC (Taylor et al. 2018), especially for community and private water systems. Drinking water quality testing only occurs during water infrastructure construction and/or in large scale surveys like Demographic and Health Surveys (DHS) and Multiple Indicator Cluster Surveys (MICS) that provide data for SDG tracking. This has raised concerns that SDG 6 monitoring lacks spatial context (Satterthwaite, 2015) and, if poorly timed, will miss seasonal variations in faecal contamination (Jewitt et al., 2018; Kostyla et al., 2015; Kumpel et al., 2017); ultimately underestimating the levels of faecal concentration in drinking water and the number of people exposed to associated health risks. This underscores the need for geographically informed understandings of the extent to which faecal contamination of drinking water varies spatially and seasonally and the implications of this for determining when to monitor drinking water for faecal contamination in situations where frequent monitoring is not feasible.

Previous [geographical] research on drinking water in LMIC contexts have made significant contributions to knowledge of the interconnections between human, hydrological and ecological systems in potable water availability (Fonstad, 2013). It has also drawn attention to the health and livelihood implications of poor access to reliable, good quality drinking water and how these vary by factors like class, gender, age and income (Bakker, 2007; Boateng et 
al., 2013; McDonald et al., 2011; O'Hara et al., 2008; O'Reilly et al., 2009; Pullan et al., 2014; Sultana, 2009; 2011; Truelove, 2011; Wagah et al., 2010). However, scholarly works on seasonal variations in faecal contamination of drinking water sources is limited in the literature. Also, the few studies that have explored this issue have produced mixed findings (Kostyla et al., 2015). In an effort to enhance understanding of this subject, we explored spatial and seasonal variations in faecal contamination of drinking water sources and key factors underpinning these in the Jirapa and Kassena-Nankana Municipalities of Ghana using Bartram et al.'s (2001) risk assessment and risk management of water-related infectious diseases model (Fig. 1). The work is structured around four key objectives; examine seasonal and spatial variations in faecal coliform concentrations in drinking water; explore the compliance of drinking water sources to faecal contamination guidelines, investigate spatial/seasonal variations in population exposure to faecal contamination through drinking water sources, and finally, identify key causes of faecal contamination of drinking water sources.

The paper highlights spatial and temporal variations in faecal contamination of drinking water and the implications of this for human health in geographical regions with high levels of seasonality. Arguments are made for water quality testing in such regions to take place when faecal coliform concentrations are likely to be at their highest to avoid underestimating contamination levels and mis-classifying 'improved' water services as 'safely managed'. These insights have relevance for both monitoring and meeting SDG 6.1 in Ghana and beyond as well as for water and sanitation researchers, practitioners and policy-makers seeking to improve water quality, monitoring and public health in LMIC contexts. 


\section{Conceptual Framework}

The study adapted Bartram et al.'s (2001) framework for safe water supply. The framework involves a systematic risk assessment and risk management of drinking water supply from catchment to the consumer aimed at preventing water-related infectious diseases (Bartram et al., 2001). The framework is cyclical in nature, comprising assessment of public health status, assessment of health risk, interpretation of risk based on health targets and risk management (Fig. 1). The framework further shows that risk assessment and risk management can be informed by assessment of environmental exposures. With emerging evidence of seasonal variations (Koystyla et al., 2015; Kumpel et al., 2016) and widely reported spatial disparities (Bain et al., 2014; Onda et al., 2012; UNICEF and WHO, 2019) in faecal contamination of drinking water sources, we recommend that assessment of faecal risk in drinking water sources using Bartram's et al. framework should pay attention to spatial and temporal variations (Fig. 1). This would help in area-based targeting and timing of risk management interventions, especially in resource-poor settings.

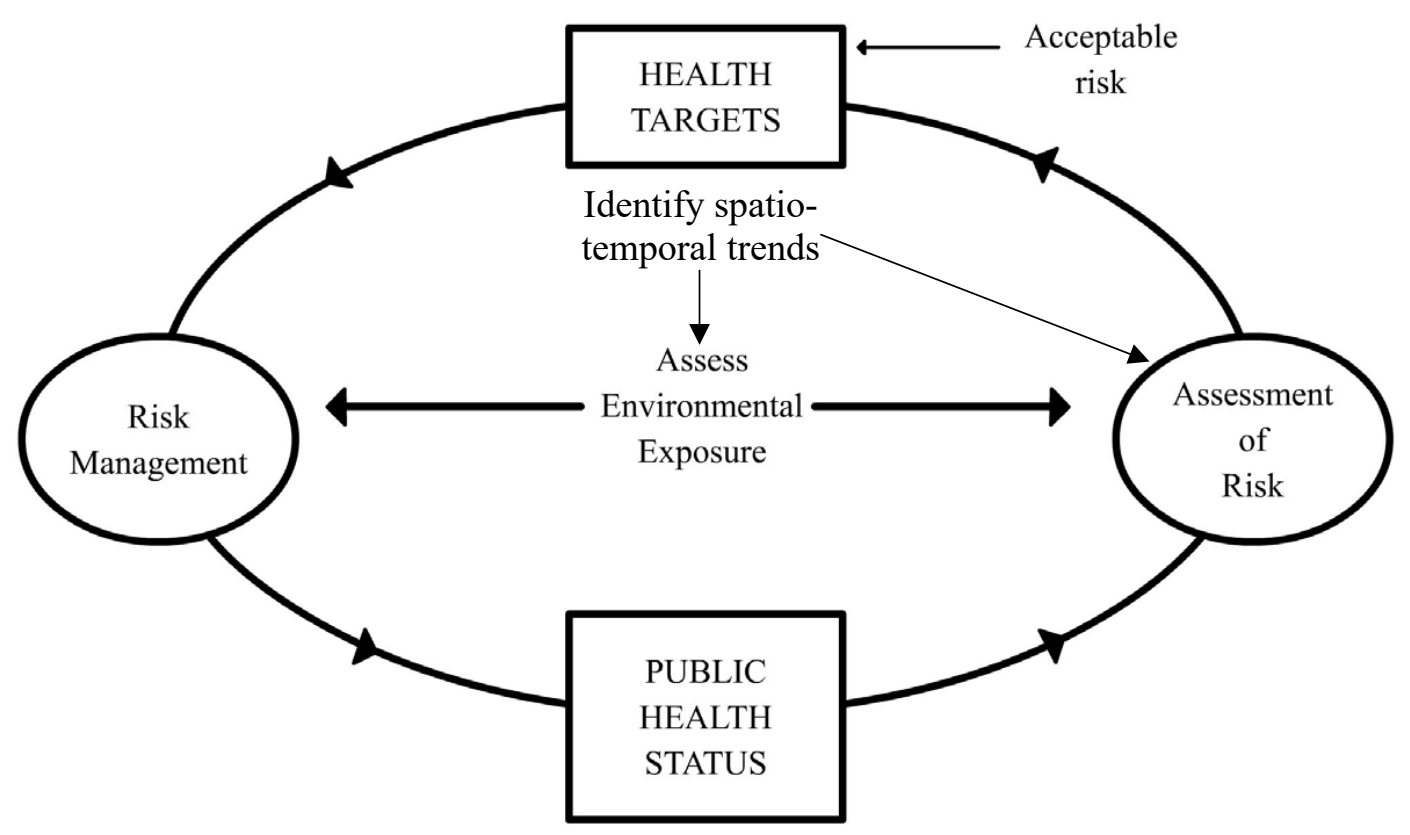

Fig. 1. Framework for risk assessment and risk management of water-related infectious diseases (Adapted from: Bartram et al., 2001) 
In line with the framework, the risk assessed in this study was faecal concentration in drinking water sources with the indicator being faecal coliforms. To better informed risk management, the study also assessed environmental related factors that expose drinking water sources to contamination. Analysis of faecal concentrations in drinking water sources and environmental exposures were done in both the rainy and dry seasons, and results disaggregated by space (Municipalities) as recommended by the framework. Faecal concentrations recorded in water samples were interpreted based on the WHO and Ghana Standard Authority health guidelines. As reported in section 1, both organisations recommend that drinking water sources must be free from E. coli or faecal coliforms (WHO, 2011; GSA, 2019).

\section{Methodology}

\subsection{Study setting}

The study was conducted in the Upper West and Upper East Regions of Ghana. Three main factors informed the selection of the Upper Regions of Ghana for this study. Firstly, the regions have two distinct seasons (rainy and dry), making them suitable for the analysis of seasonal variation in faecal contamination. Secondly, the regions are characterised by poor sanitation access and use with 2017 MICS data indicating that $67 \%$ and $52 \%$ of population in the Upper East and Upper West Regions, respectively, practised open defecation (GSS et al., 2018). This increases the risk of groundwater - the main source of drinking water - to faecal contamination. Finally, the lead author is familiar with the geography of the Upper West and Upper East regions of Ghana, which facilitated access to community members and water sources following the granting of consent from gatekeepers. Jirapa Municipality in the Upper 
West Region and Kassena-Nankana Municipality in the Upper East Region (Fig. 2) were selected for the study through a simple random sample.

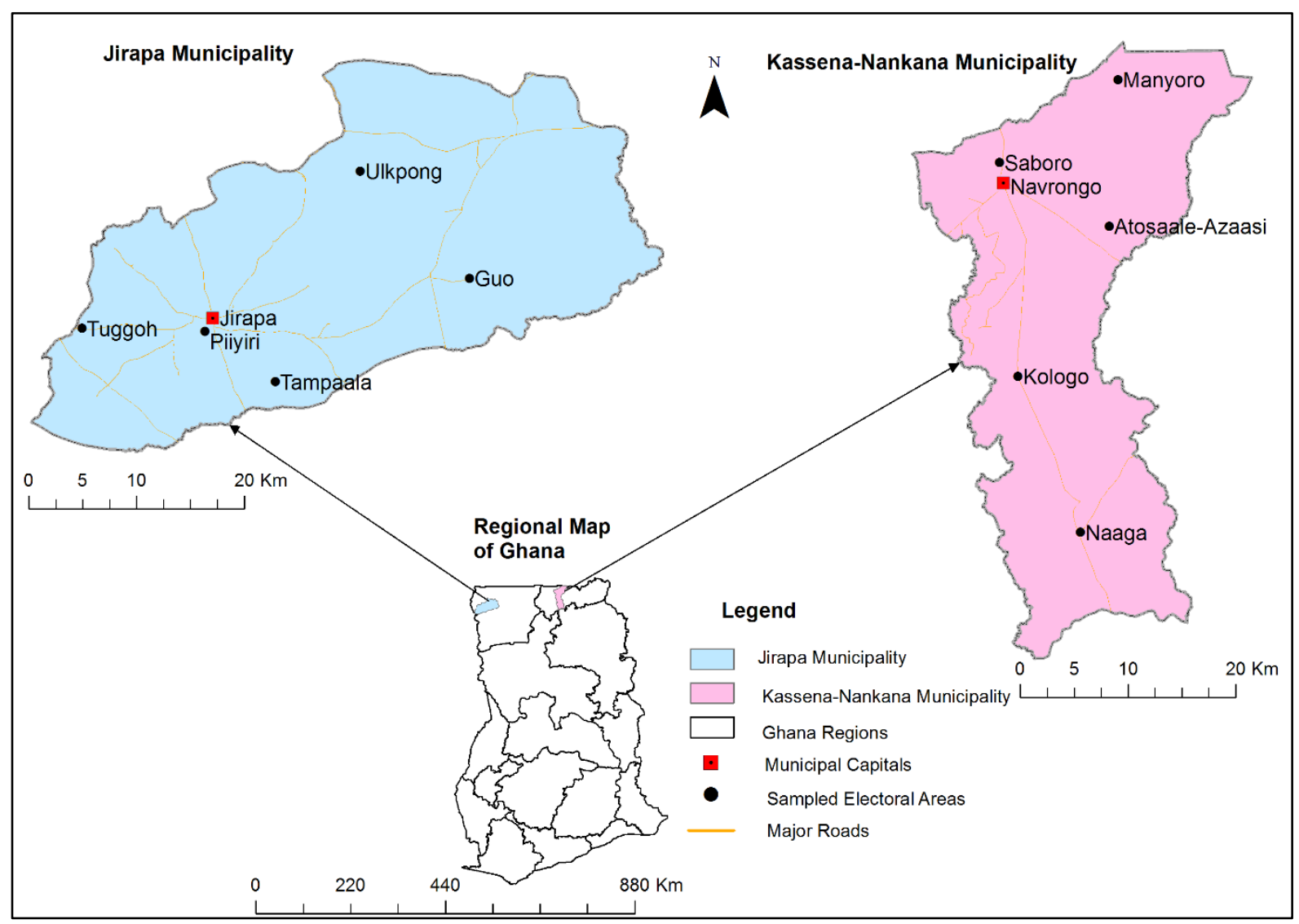

Fig. 2. Map of Ghana showing location of study Municipalities

Kassena-Nankana Municipality is one of the 13 districts/municipalities in the Upper East Region of Ghana with the capital being Navrongo. It falls within the tropical continental climatic zone with one rainy season (GSS, 2013b). The average annual rainfall is estimated to be $950 \mathrm{~mm}$ (GSS, 2013b). Rainfall starts in April with a low monthly average of about 30mm, increasing to a high of $260 \mathrm{~mm}$ in August. It reduces suddenly to $50 \mathrm{~mm}$ at the end of the rainy season in September (Agyekum and Dapaah-Siakwan, 2008). The rest of the year remains dry. Average monthly temperature ranges from $26.5-33^{\circ} \mathrm{C}$ and between January and April, daily temperature can be as high as $42^{\circ} \mathrm{C}$ (Agyekum and Dapaah-Siakwan, 2008). From the 2010 Population and Housing Census (PHC), the municipality recorded a total population of 109,944 
with 70\% living in rural areas (GSS, 2014b). To help gain insight into the environmental factors that exposed drinking water sources to faecal contamination in Kassena-Nankana Municipality (Fig. 1), census data on trends in access to improved water and sanitation sources were examined. The data show that $93.2 \%$ of households mainly used improved water sources. Of these, $64.6 \%$ used boreholes, $15.2 \%$ used piped water systems, $9.9 \%$ used protected hand-dug wells, $2.5 \%$ used public tap/standpipes, $0.4 \%$ used bottled/sachet water, $0.3 \%$ used rainwater, $0.2 \%$ used protected springs and $0.1 \%$ used tanker/vendor supply as their main drinking water source (GSS, 2014b). The remaining 6.8\% of households relied mainly on unimproved sources, comprising of unprotected hand-dug wells, rivers, streams, dams, dugouts, canals and ponds. Poor sanitation practices in the municipality increased the vulnerability of drinking water sources to faecal contamination. According to the 2010 PHC, only $10.2 \%$ of households had access to improved toilets (GSS, 2014b). The remainder practised open defecation $(83.7 \%)$ or used other unimproved toilet facilities $(6.1 \%)$.

The second study municipality, Jirapa, is one of the 11 districts/municipalities in the Upper West Region of Ghana. It is situated in the north-western part of Ghana with Jirapa as its capital. Like the Kassena-Nankana Municipality, Jirapa Municipality also experiences a single maxima rainfall regime from late April to September, with average annual rainfall of about $115 \mathrm{~cm}$ (GSS, 2013a). The other half of the year remains dry. The average monthly temperature ranges between $21^{\circ} \mathrm{C}$ and $32{ }^{\circ} \mathrm{C}$. Temperatures rise to a maximum of around $40{ }^{\circ} \mathrm{C}$ in $\mathrm{March}$, just before the onset of the rainy season (GSS, 2013a). Data from the 2010 PHC shows that the municipality had a total population of 88,402 in 2010 with $85.6 \%$ of the population living in rural areas and reliant on subsistence agriculture as their main source of livelihood (GSS, 2014a). The sources of drinking water in the municipality include pipe-borne sources, standpipes, boreholes, hand-dug wells, rivers/streams, tanker/vendor supply, rainwater, sachet water and dam/dugouts. Results of the 2010 PHC showed that $91.6 \%$ of households used 
improved drinking water sources, mainly boreholes $(75.1 \%)$, as their main drinking water source. Like the Kassena-Nankana Municipality, sanitation practices in Jirapa Municipality also leave much to be desired with only $7.6 \%$ having access to improved facilities (GSS, 2014a). A majority (81.3\%) of households practise open defecation with a few using other unimproved toilet facilities (11.1\%) (GSS, 2014a).

\subsection{Data collection}

To achieve the objectives of the study, primary data on faecal concentration in household drinking water sources as well as the causes of contamination were required for both rainy and dry seasons. The study therefore adopted a mixed method approach to data collection (Creswell, 2007; Creswell and Clark 2011) which took place in Ghana from June 2017 to February 2018. The rationale was to maximise the benefits of both qualitative and quantitative methods in order to provide a comprehensive understanding of faecal contamination of drinking water sources (Creswell, 2007; Creswell and Clark, 2011). Four main data collection methods $^{3}$ were employed including a household survey, testing of faecal concentrations in household drinking water sources, in-depth interview with hydrogeologists from the Community Water and Sanitation Agency (CWSA) plus field observations in the study sites.

\section{a. Household survey}

A household survey was used to collect data on household size and to also identify households' main drinking water sources for faecal testing (refer to section $3.2 \mathrm{~b}$ for faecal testing). A representative sample of 395 households was determined for the study based on Taro's (1973) sample size formula;

$$
\mathrm{n}=\mathrm{N} /\left(1+\mathrm{Ne}^{2}\right)
$$

\footnotetext{
${ }^{3}$ As this paper draws from the lead author's doctoral research, the data collection methods presented here are limited to those relevant to this article.
} 
Where

$$
\begin{aligned}
& \mathrm{n}=\text { Sample size } \\
& \mathrm{N}=\text { Population }(33,701)^{4} \\
& \mathrm{e}=\text { Sampling error }( \pm 5 \%)
\end{aligned}
$$

The intention was to distribute the sample (395) proportionally between the two study municipalities - Jirapa (163) and Kassena Nankana (232) but to enhance reliability, the target sample was increased during data collection. In total, data were gathered from 568 households; 268 in Jirapa Municipality and 300 in Kassena Nankana Municipality. In each Municipality, households were randomly drawn from five Electoral Areas (Fig. 2) sampled from five clustered zones: North, South, East, West and Central.

The survey was administered to householders using SurveyCTO mobile data collection technology. Due to high illiteracy levels in the study area, research assistants were trained to help administer it in the local dialects (Dagaare, Kasim and Nankam). The survey was targeted at adult household members with responsibility for household management and water collection; most of whom were female. Data were downloaded from the SurveyCTO platform as an csv file and exported to Statistical Package for Social Sciences (SPSS) for analysis.

\section{b. Testing of faecal concentration in household drinking water sources}

Testing of faecal concentration in drinking water sources was conducted in all sampled households (refer to section 3.2a for sampling design). Water samples were collected from households' main drinking water sources and tested in two rounds; first, in the rainy season, and second, in the dry season. The rainy season water sample collection took place during the peak of the season, from June - August 2017 while the dry season collection took place from January to February, 2018. Water samples were collected with $400 \mathrm{~mL}$ plastic bottles which were sterilised to prevent cross-contamination. Methylated spirit was first used to disinfect

\footnotetext{
${ }^{4}$ Total number of households for both Jirapa and Kassena-Nankana Municipalities recorded in the 2010 Population and Housing Census (GSS, 2013a;2013b)
} 
bottles, followed by distilled water to clear any residual methylated spirit. The bottles were then rinsed three times with source water before samples were drawn.

A total of 141 water samples, from six different water sources were collected in the rainy season (Table 1). In the dry season, a total of 128 water samples were collected - a reduction of 13 samples if compared to the 141 samples collected in the rainy season. With the exception of pipe-borne water, there was a slight reduction in the number of water samples collected in the dry season compared to the rainy season (Table 1). This was largely due to break downs of water infrastructure in the case of borehole and standpipe sources while some protected/unprotected wells and dugouts/dams dried up in the dry season. In both seasons, the number of water samples collected was less than the number of households surveyed because most households share water sources. It is worth mentioning that the large disparity in samples from boreholes compared to other sources limits the comparison of results by source types.

Table 1. Number of water samples collected and tested by source types in the rainy and dry seasons

\begin{tabular}{|c|c|c|c|c|c|c|}
\hline \multirow[b]{2}{*}{ Source types } & \multicolumn{3}{|c|}{ Rainy Season } & \multicolumn{3}{|c|}{ Dry Season } \\
\hline & $\mathbf{J M}$ & KNM & Total & $\mathbf{J M}$ & KNM & Total \\
\hline Pipe-borne ${ }^{5}$ & 5 & 5 & 10 & 5 & 5 & 10 \\
\hline Public tap/standpipe 6 & 1 & 4 & 5 & 1 & 3 & 4 \\
\hline Borehole & 52 & 57 & 109 & 49 & 56 & 105 \\
\hline Protected well & 1 & 7 & 8 & 1 & 6 & 7 \\
\hline Unprotected well & 4 & 3 & 7 & 1 & 1 & 2 \\
\hline Dugout/Dam & 1 & 1 & 2 & 0 & 0 & 0 \\
\hline Total & 64 & 77 & 141 & 57 & 71 & 128 \\
\hline
\end{tabular}

JM (Jirapa Municipality); KNM (Kassena-Nankana Municipality)

Source: Field survey, 2017/2018

Testing of faecal concentration in drinking water sources was carried out using $3 \mathrm{M}$ Petrifilm Coliform Count Plates with the faecal indicator bacteria being faecal coliform. Petrifilms are

\footnotetext{
${ }^{5}$ Network water supply system via a household tap

${ }^{6}$ Mechanised boreholes
} 
portable and easy to use sample-ready-culture plating systems designed by the food safety division of $3 \mathrm{M}$ Corporation for the enumeration of coliforms in the food and beverage industries. Though originally designed for microbial testing in food and beverages, they have proven to be strongly correlated and statistically significant with traditional methods of microbial analysis in water such as Most Probable Number (MPN) and membrane filtration (Schraft and Watterworth, 2005; Vail et al., 2003). For each water sample, a 3M Petrifilm Coliform Count plate was inoculated with $1 \mathrm{~mL}$ of water sample and incubated at $44{ }^{0} \mathrm{C}$ for 24 hours +/- 2 hours based on NF V08 060 reference method (Adria Development et al., 2014) using HIS25 Rocking Hybridisation Incubator. Incubation began not more than five hours after sample collection. Where faecal coliforms were present in water, they grew on plates as red colonies with or without gas bubbles after incubation (Adria Development et al., 2014). Colonies were counted and expressed as Colony Forming Units (CFU)/ 1mL. To enhance the reliability of the results, replicate test was conducted for about $20 \%$ of water samples in both rainy and dry seasons by incubating two different $3 \mathrm{M}$ Petrifilm coliform count plates with the same water sample. It is gratifying to mention that all replicate tests produced the same results. Nonetheless, it must be pointed out that water sample bottles were without sodium thiosulfate, and hence treated pipe-borne water risk producing false negative results due to residual chlorine.

\section{c. In-depth interviews with Hydrogeologists of Community Water and Sanitation Agency}

In both Jirapa and Kassena Nankana Municipalities, in-depth interviews were conducted with hydrogeologists from the CWSA to elicit their views on faecal contamination of drinking water sources, risk factors causing faecal contamination of drinking water sources as well as risk management interventions in their respective districts. The interviews were semi- 
structured to allow for an in-depth discussion of the subject matter. However, an interview schedule was prepared to guide discussions.

\section{d. Field observation}

In addition to in-depth-interviews held with hydrogeologists of the CWSA, a sanitary inspection was also carried out to help identify risk factors that could cause faecal contamination of drinking water sources. Drawing on literature (WHO, 2011; Kirby et al., 2016; Escamilla et al., 2013; Mkwate et al., 2016), the sanitary inspection focused on environmental sanitation practices, nearness/distance of improved water sources (e.g. boreholes) to surface water bodies, level of protection of drinking water sources, condition of water infrastructure and system of animal rearing.

\subsection{Data analysis}

Quantitative data gathered through testing of faecal coliforms in household drinking water sources were analysed using IBM Statistical Package for the Social Sciences (SPSS), version 24. Firstly, descriptive statistics were generated to understand the extent of faecal coliform concentrations in drinking water sources, and also by seasons, source types and Municipalities. Secondly, a Wilcoxon Signed Rank Test ${ }^{7}$ was carried out to ascertain if faecal coliform concentrations in drinking water sources vary significantly by seasons. Thirdly, frequencies were generated on the proportions of drinking water sources that comply or do not comply with the WHO/GSA guideline regarding faecal concentration in drinking water sources.

\footnotetext{
${ }^{7}$ A Wilcoxon Signed Rank test was suitable because it is used for comparing two sets of non-normally distributed data that comes from the same participants (Field, 2013). The normality of the data was verified based on K-S and Shapiro-Wilk normality test. From the test statistics, faecal coliform concentrations for all sources and also by source types in both rainy and dry seasons were significantly different from normal $(\mathrm{P}<0.05)$.
} 
Furthermore, percentages were generated on the extent of population exposure to faecal concentration in drinking water sources. This analysis was done in relation to the WHO E.colirisk-to-health classification (WHO, 2011a);

- $\quad<1 \mathrm{CFU} / 100 \mathrm{~mL}^{8}($ low risk $)$,

- 1-10 CFU/100mL (intermediate risk),

- 11-100 CFU/100mL (high risk) and

- $100 \mathrm{CFU} / 100 \mathrm{~mL}$ (very high risk).

Qualitative data collected through interviews and field observation on risk factors in faecal contamination of drinking water sources were analysed thematically. In some cases, photographs are presented to illustrate key findings.

\section{Results and Discussion}

\subsection{Seasonal variations in faecal contamination of drinking water sources}

Analysis of descriptive statistics revealed higher levels of faecal coliform concentrations in drinking water sources in the rainy season than in the dry season. From Tables 2 and 3, the amount of faecal coliforms in household water sources in the rainy season ranged from $0-800$ $\mathrm{CFU} / 1 \mathrm{~mL}$ with the average being $45 \mathrm{CFU} / 1 \mathrm{~mL}$ whereas in the dry season it ranged from $0-$ $600 \mathrm{CFU} / 1 \mathrm{~mL}$ with the average being $12 \mathrm{CFU} / 1 \mathrm{~mL}$ for all sources. Analysis of the average faecal coliform concentrations by source types revealed that in the rainy season, dugouts/dams recorded the highest average concentration $(420 \mathrm{CFU} / 1 \mathrm{~mL})$, followed by unprotected wells (234 CFU/1mL), protected wells (112 CFU/1mL), boreholes (29 CFU/1mL), standpipes (5 $\mathrm{CFU} / 1 \mathrm{~mL})$ and lastly pipe-borne sources $(2 \mathrm{CFU} / 1 \mathrm{~mL})$. In contrast, protected wells had the

\footnotetext{
${ }^{8}$ Adapted as $1 \mathrm{~mL}$ to reflect recommended sample volume of the $3 \mathrm{M}$ Petrifilm enumeration method employed in this study.
} 
highest average concentration in the dry season $(141 \mathrm{CFU} / 1 \mathrm{~mL})$, followed by unprotected wells (73 CFU/1mL), standpipes (13 CFU/1mL), boreholes (3 CFU/1mL) and pipe-borne (1 CFU/1mL). Regardless of season, faecal coliform concentrations in improved water sources were far lower than in unimproved water sources (Tables 2 and 3) reflecting their higher levels of protection than unimproved water sources (Agensi et al., 2019). This finding agrees largely with previous studies by GSS et al., (2015); Kirby et al., (2016); Kumpel et al., (2017) and Smiley, (2017). In both rainy and dry seasons, the average faecal coliform concentrations in Kassena-Nankana Municipality were higher than in Jirapa Municipality (Tables 2 and 3).

Table 2. Levels of faecal coliform concentrations $(\mathrm{CFU} / 1 \mathrm{~mL})$ in drinking water sources in the rainy season

\begin{tabular}{|c|c|c|c|c|c|c|c|c|c|}
\hline \multirow[t]{2}{*}{ Source types } & \multicolumn{3}{|c|}{ Jirapa Municipality } & \multicolumn{3}{|c|}{$\begin{array}{l}\text { Kassena-Nankana } \\
\text { Municipality }\end{array}$} & \multicolumn{3}{|c|}{ Both Municipalities } \\
\hline & Min. & Max. & Aveg. & Min. & Max. & Aveg. & Min. & Max. & Aveg. \\
\hline Pipe-borne & 0 & 2 & 0.4 & 0 & 13 & 13.2 & 0 & 13 & 2 \\
\hline Public tap/standpipe & 14 & 14 & 14 & 0 & 6 & 3.3 & 0 & 14 & 5 \\
\hline Borehole & 0 & 800 & 24.3 & 0 & 640 & 33.5 & 0 & 800 & 29 \\
\hline Protected well & 280 & 280 & 280 & 22 & 240 & 88.1 & 22 & 280 & 112 \\
\hline Unprotected well & 82 & 440 & 262 & 51 & 420 & 196.7 & 51 & 440 & 234 \\
\hline Dugouts/Dam & 420 & 420 & 420 & 104 & 104 & 104 & 104 & 420 & 262 \\
\hline Improved sources & 0 & 800 & 26.4 & 0 & 640 & 35 & 0 & 800 & 31 \\
\hline Unimproved sources & 82 & 440 & 293.6 & 51 & 420 & 173.5 & 51 & 440 & 240 \\
\hline All sources & 0 & 800 & 47.3 & 0 & 640 & 42 & 0 & 800 & 44.5 \\
\hline
\end{tabular}

Source: Field survey, 2017 
Table 3. Levels of faecal coliform concentrations $(\mathrm{CFU} / 1 \mathrm{~mL})$ in drinking water sources in the dry season

\begin{tabular}{lcccccccccc}
\hline Source types & \multicolumn{1}{c}{ Jirapa Municipality } & \multicolumn{3}{c}{$\begin{array}{l}\text { Kassena-Nankana } \\
\text { Municipality }\end{array}$} & \multicolumn{3}{c}{ Both Municipalities } \\
& \multicolumn{1}{c}{ Min. } & Max. & Aveg. & Min. & Max. & Aveg. & Min. & Max. & Aveg. \\
\hline Pipe-borne & 0 & 3 & 1 & 0 & 0 & 0 & 0 & 3 & 1 \\
Public tap/standpipe & 0 & 0 & 0 & 0 & 50 & 17 & 0 & 50 & 13 \\
Borehole & 0 & 15 & 0.6 & 0 & 180 & 6 & 0 & 180 & 3 \\
Protected well & 69 & 69 & 69 & 13 & 600 & 153.5 & 13 & 300 & 141 \\
Unprotected well & 45 & 45 & 45 & 101 & 101 & 101 & 45 & 101 & 73 \\
Dugouts/Dam & - & - & - & - & - & - & - & - & - \\
Improved sources & 0 & 69 & 2 & 0 & 600 & 18.7 & 0 & 600 & 11 \\
Unimproved sources & 45 & 45 & 45 & 101 & 101 & 101 & 0 & 101 & 73 \\
All sources & 0 & 69 & 2.6 & 0 & 600 & 19.8 & 45 & 600 & 12.2 \\
\hline Source: Fidd
\end{tabular}

Source: Field survey, 2017

The Wilcoxon Signed Rank test statistics revealed significant differences $(z=-0.53, p<$ $0.05, \mathrm{r}=-0.41)$ in faecal coliform concentrations in drinking water between rainy and dry seasons for all sources (Table 4). This is consistent with studies by Kostyla et al. (2015) and Kumpel et al. (2017). The results also revealed significant seasonal variations in faecal coliform concentrations for improved water sources $(\mathrm{z}=-4.39, \mathrm{P}<0.05, \mathrm{r}=-0.39)$. For unimproved water sources, the results show no significant seasonal variation in faecal coliforms $(\mathrm{z}=-1.342$, $\mathrm{P}>0.05, \mathrm{r}=-0.12$ ). Seasonal variations in faecal coliform concentrations are statistically significant for all source types except boreholes $(\mathrm{P}>0.05)$ for both study Municipalities (Table 4). A segregated analysis by Municipality revealed that in both Jirapa and Kassena-Nankana Municipalities, the differences in faecal coliform concentrations in the rainy and dry seasons for all water sources were statistically significant (Table 4). 
Table 4. Wilcoxon Signed Rank Test statistics on the level of significance or otherwise of seasonal differences in faecal coliform concentrations in drinking water sources

\begin{tabular}{|c|c|c|c|c|c|c|}
\hline \multirow[b]{2}{*}{ Source types } & \multicolumn{2}{|c|}{$\begin{array}{c}\text { Jirapa } \\
\text { Municipality }\end{array}$} & \multicolumn{2}{|c|}{$\begin{array}{c}\text { Kassena- } \\
\text { Nankana } \\
\text { Municipality }\end{array}$} & \multicolumn{2}{|c|}{ Both Municipalities } \\
\hline & $\begin{array}{c}\mathrm{Z} \\
\text { score }\end{array}$ & $\begin{array}{c}\text { P value } \\
\text { (2-tailed) }\end{array}$ & $\begin{array}{c}\mathrm{Z} \\
\text { score }\end{array}$ & $\begin{array}{l}\text { P value } \\
\text { (2-tailed) }\end{array}$ & $\mathrm{Z}$ score & $\begin{array}{c}\text { P value } \\
\text { (2-tailed) }\end{array}$ \\
\hline Pipe-borne & -0.816 & 0.414 & -1.604 & 0.109 & -.530 & 0.596 \\
\hline Public taps/standpipes & $*$ & $*$ & 0.00 & 1.000 & -.365 & 0.715 \\
\hline Boreholes & -2.399 & 0.016 & -3.423 & 0.001 & -4.294 & 0.000 \\
\hline Protected wells & $*$ & $*$ & -0.734 & 0.463 & -1.014 & 0.310 \\
\hline Unprotected wells & $*$ & * & $*$ & $*$ & -1.342 & 0.180 \\
\hline Improved sources & -2.458 & 0.014 & -3.450 & 0.001 & -4.390 & 0.000 \\
\hline Unimproved sources & $*$ & $*$ & $*$ & $*$ & -1.342 & 0.180 \\
\hline All sources & -2.650 & 0.008 & -3.579 & 0.000 & -4.599 & 0.000 \\
\hline
\end{tabular}

Source: Field survey, 2017

\subsection{Level of compliance of drinking water sources to faecal contamination guideline}

On health grounds, both the WHO and GSA recommend that drinking water sources must not contain E.coli or faecal coliform (GSA, 2019; WHO, 2011). From Fig. 3, compliance of drinking water sources to the WHO/GSA faecal coliform guideline was generally high in the dry season compared to the rainy season. For all sources, $27.3 \%$ of samples in the dry season and $51.8 \%$ in the rainy season contained faecal coliforms and thus failed to comply with the guideline while all unimproved water samples failed to comply regardless of season. Among the four different types of improved water sources for which samples were collected and tested, the level of compliance was generally high for pipe-borne sources, followed by boreholes, standpipes and lastly protected wells. Although protected wells are classed as an improved water source, all samples, irrespective of season, contained faecal coliforms. 
-Without Faecal Coliform $\quad$ With Faecal Coliform

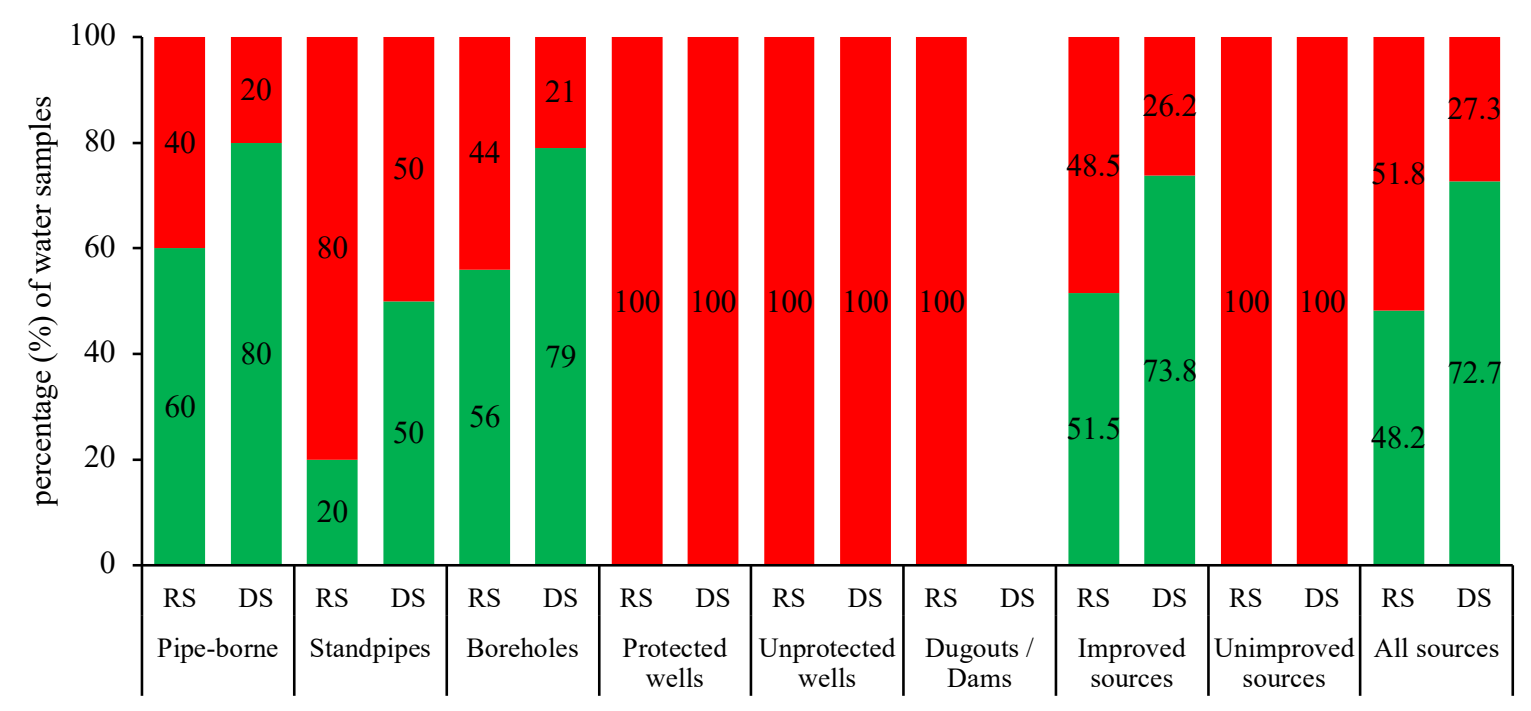

RS (Rainy Season); DS (Dry Season)

Fig. 3. Proportion of water samples with or without faecal coliforms $(\mathrm{CFU} / 1 \mathrm{~mL})$ in both study municipalities

The results presented in Fig. 3 echo the findings of the 2014 Ghana Demographic Health Survey (GSS et al., 2015) which revealed an E-coli compliance level of 56.5\% for all drinking water sources with significant differences between improved (51.2\%) and unimproved (29.2\%) water sources. In the same DHS, compliance was highest for sachet/bottled water samples (89.2\%), followed by water from pipe-borne sources (70\%), standpipes $(52.8 \%)$, boreholes (47\%), protected hand-dug wells (31\%), surface water (29.1\%) and unprotected hand-dug wells (9.9\%). In contrast to the DHS data, all samples in this study from protected hand-dug wells, surface water and unprotected hand-dug wells failed to comply. Our detection of faecal coliforms in $44 \%$ and $21 \%$ of borehole samples respectively in the rainy and dry season also differ significantly from the work of Arnold et al. (2013) in the Ashanti Region of Ghana which did not find E. coli in any borehole samples. Our identification of faecal coliforms in all dug well (protected and unprotected wells) and surface water (dugout/dam) samples also contrasts with Arnold et al.'s findings that $72 \%, 33 \%$ and $20 \%$ of samples from dug wells, rivers and shallow wells were free from E.coli, respectively. The above highlighted differences in findings 
between this study and the 2014 DHS and Arnold et al. (2013) could largely be attributed to poor sanitation practices in the study regions (Upper West ad Upper East) compared to other regions in Ghana (Ghana Statistical Service, 2018).

The level of compliance with the WHO/GSA faecal guideline varies between the two study districts with Jirapa Municipality outperforming Kassena-Nankana District. In the rainy season, $59.5 \%$ of samples in the Jirapa Municipality complied with the guideline as against $39.0 \%$ in Kassena-Nankana Municipality although in both districts all samples from unimproved sources failed to comply (Fig. 4 and 5).

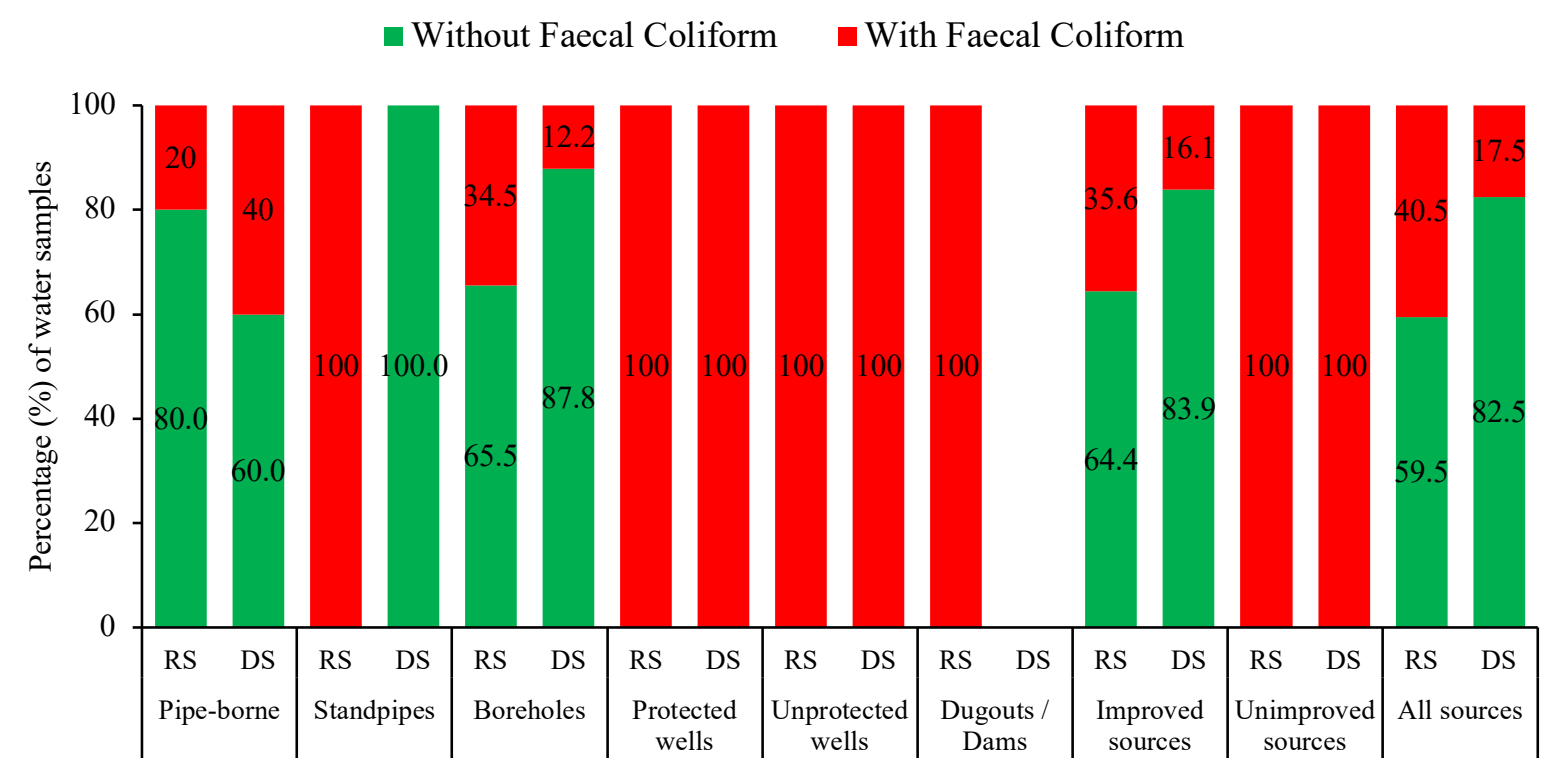

RS (Rainy Season); DS (Dry Season)

Fig. 4. Proportion of water samples with or without faecal coliforms $(\mathrm{CFU} / 1 \mathrm{~mL})$ in the Jirapa Municipality 


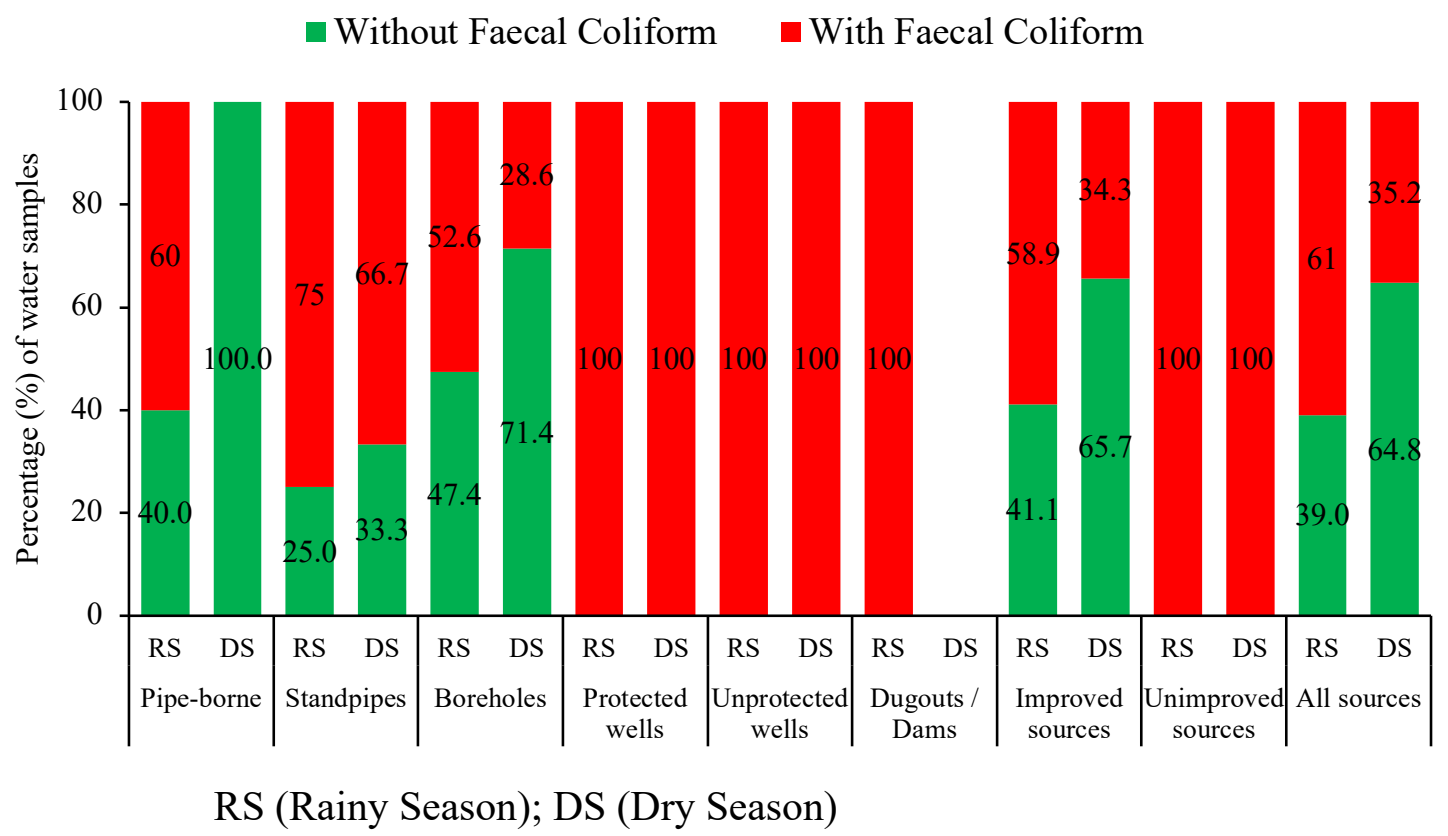

Fig. 5. Proportion of water samples with or without faecal coliforms $(\mathrm{CFU} / 1 \mathrm{~mL})$ in the Kassena-Nankana Municipality

\subsection{Level of population exposure to faecal concentration in drinking water sources}

The results showed that $33.1 \%$ of the sample population's drinking water sources was contaminated with faeces in the dry season (Fig. 6). In the rainy season, it increased to $41.5 \%$ (Fig. 6). The proportions of the population exposed to faecal contaminated water in the rainy and dry seasons were lower than the Joint Monitoring Programme's estimate of $43 \%$ in 2012/2013 for Ghana (UNICEF and WHO, 2019). This reduction can be attributed to an increase in improved water coverage in Ghana from 79.3\% in 2011 to $88 \%$ in 2015 (GSS, $2011 ; 2018)$. In terms of risk levels, the proportion of population at intermediate $(22.3 \% \mathrm{vs}$ $15.1 \%)$, high $(10.4 \%$ vs $8.4 \%)$ and very high $(8.8 \%$ vs $1.6 \%)$ levels of risk of faecal contamination in the rainy season were moderately higher than in the dry season (Fig. 6). Regardless of season, the proportion of population at risk of faecal contamination in KassenaNankana Municipality is significantly higher than in Jirapa Municipality. For instance, in the rainy season, $52.4 \%$ of population drinking water sources in Kassena-Nankana Municipality 
are at risk of faecal contamination compared to $31.5 \%$ in Jirapa Municipality (Fig. 7 and 8). Insights into the factors accounting for these spatial differences are reported in section 4.4.

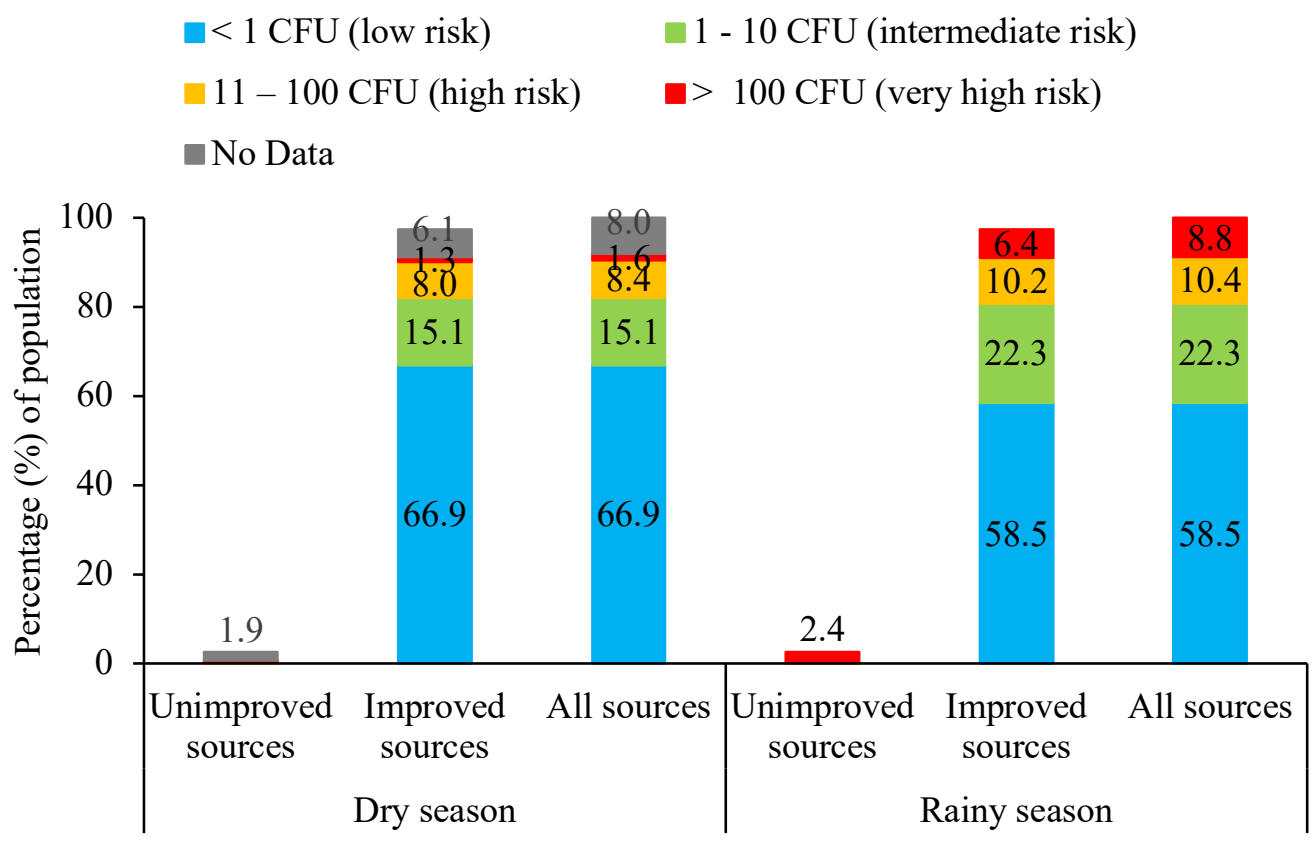

Fig. 6. Distribution of population by levels of faecal coliform concentration in drinking water sources in both study Municipalities

Source: Field survey, 2017

A disaggregated analysis by improved and unimproved water sources revealed that $38.9 \%$ of the population using improved drinking water sources in the rainy season and $24.4 \%$ in the dry season were at intermediate or higher risk of faecal contamination (Fig. 6). It is disturbing to note that $16.8 \%$ and $9.3 \%$ (out of the $97.6 \%$ and $91.3 \%$ using improved drinking water) respectively in the rainy and dry seasons were at very high or high levels of risk of faecal contamination (Fig. 6). In both rainy and dry seasons, the proportion of improved water source users exposed to faecal contamination in Kassena-Nankana Municipality was higher than in Jirapa Municipality (Fig. 7 and 8). In the rainy season, $52.7 \%$ (out of $98.3 \%$ ) of the population using improved water in Kassena-Nankana Municipality were at an intermediate or higher risk of faecal contamination compared to $28.1 \%$ (out of $96.6 \%$ ) in Jirapa Municipality. 


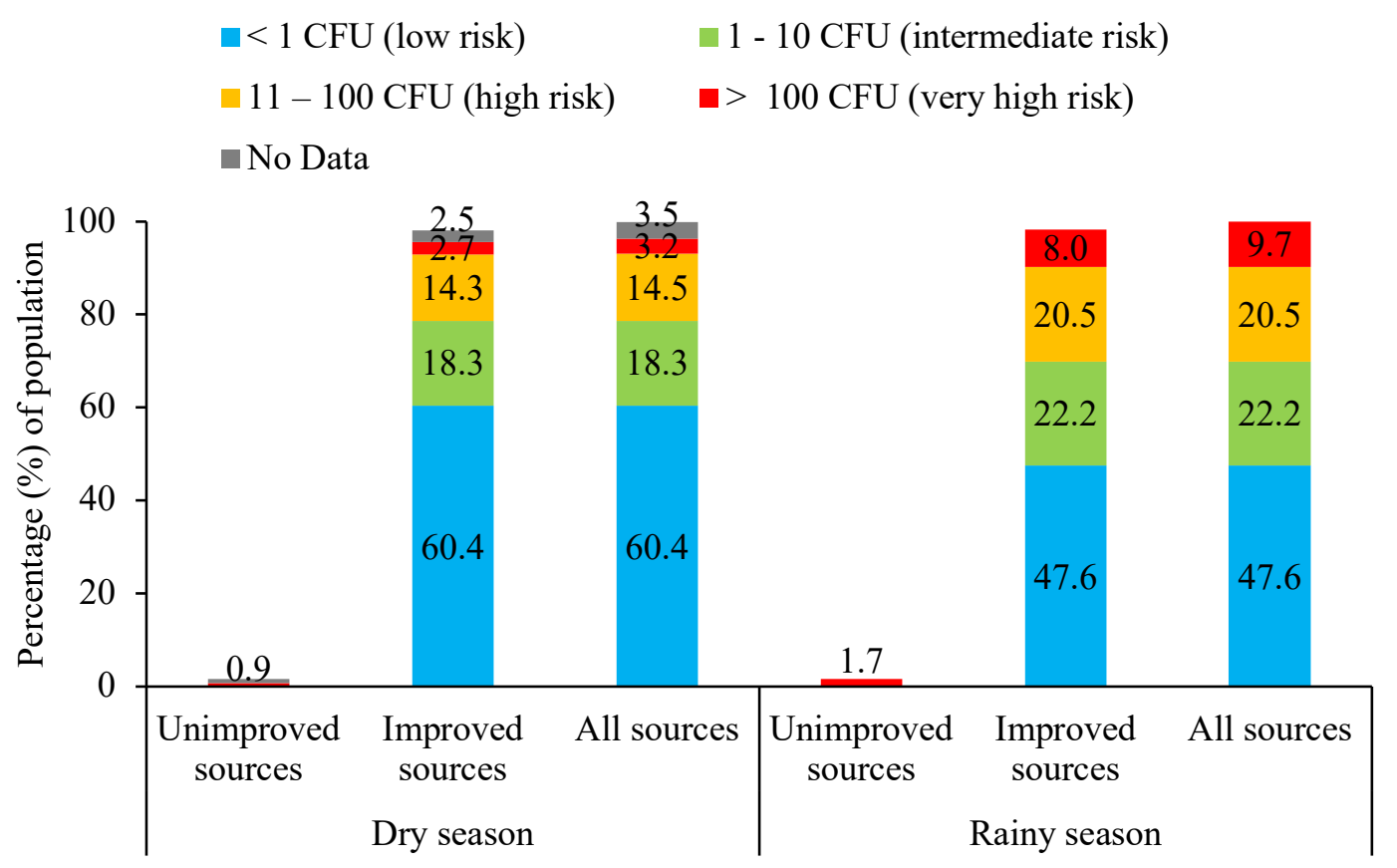

Fig. 7. Distribution of population by levels of faecal coliforms concentration in drinking water sources in Kassena-Nankana Municipality

Source: Field survey, 2017



Fig. 8. Distribution of population by levels of faecal coliform concentrations in drinking water sources in Jirapa Municipality

Source: Field survey, 2017 


\subsection{Risk factors in faecal contamination of drinking water sources}

Interviews with key stakeholders coupled with on-site observations showed that faecal contamination of drinking water sources in the study sites is linked to four main factors with slight spatio-temporal differences. Firstly, poor management of water sources resulted in leaks, cracks and loosed joints around water infrastructure (Fig. 10). In the case of boreholes, these openings acted as routes for the seepage of faecal matter into wells. With regards to network infrastructure, these leaks, cracks and loose joints coupled with intermittent water supply exposed water supply systems to a risk of faecal contamination (WHO, 2011; Klasen et al., 2012). Poor management of water sources also took the form of inadequate protection of water sources against animals. In all study communities, water users allowed animals to drink wastewater from troughs, especially at borehole sites (Fig. 9) which resulted in animal faeces gaining ingress through available openings. Furthermore, water infrastructures (especially boreholes) were reported to be poorly maintained. An in-depth interview with the hydrogeologist of CWSA in Kassena Nankana Municipal revealed that boreholes are supposed to be re-developed ${ }^{9}$ every 10 years to clear algae, worms and blockages inside wells. However, compliance with such recommendations was low due to the high cost of such redevelopment work. Acknowledging this, the CWSA encourages routine disinfection of wells and cleaning of pipes but these were also reported to be rarely done. From the interviews and on-site observation of water infrastructure, poor management of drinking water sources was more widespread in Kassena-Nankana Municipality than Jirapa Municipality. This, in part, explains why more drinking water sources in Jirapa meet the WHO guideline, whereas a higher share of population is exposed to risk in Kassena-Nankana.

\footnotetext{
${ }^{9}$ Underground well maintenance
} 


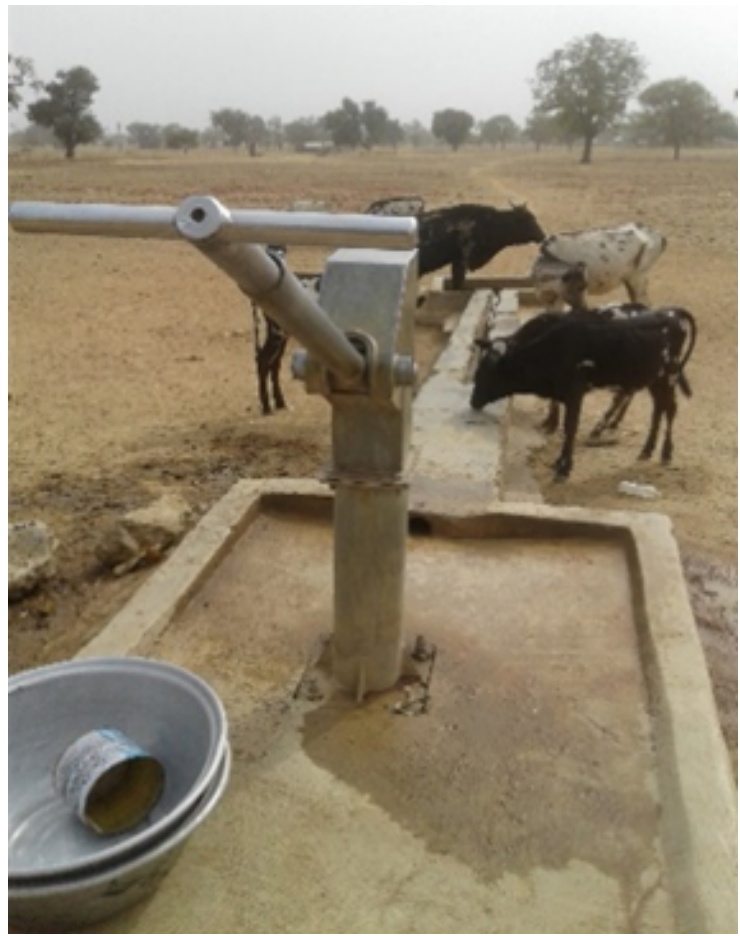

Source: Field survey, February 2018

Fig. 9. Cows drinking from a borehole in Atosaale, Kassena Nankana Municipality

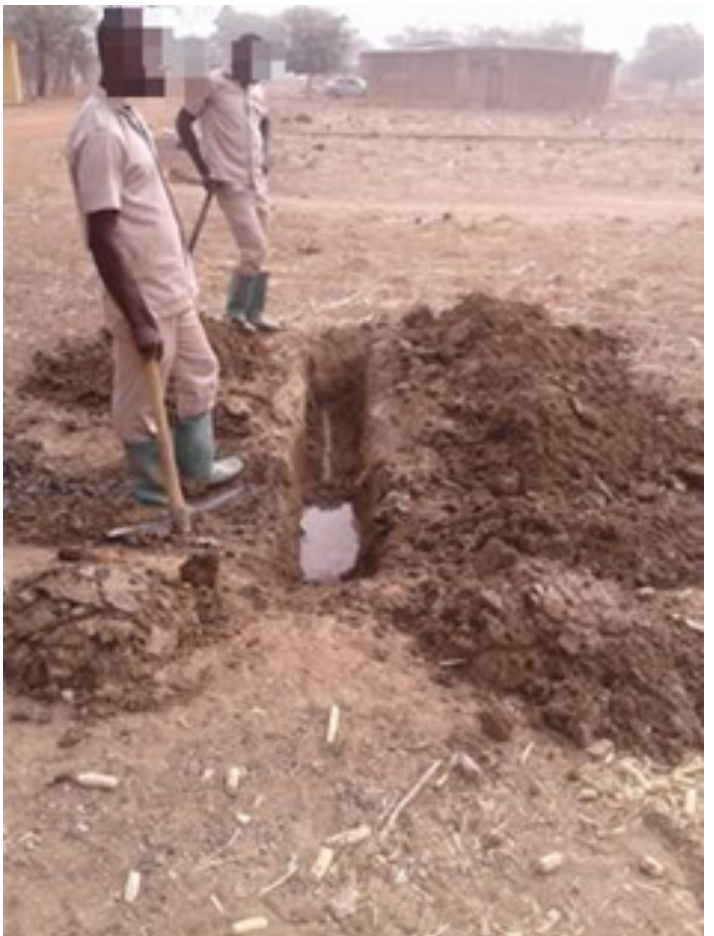

Source: Field survey, February 2018

Fig. 10. Staff of GWCL, repairing a leaking pipe in Navrongo, Kassena Nankana Municipality

The study also identified poor sanitation practices as another environmental exposurerelated risk factor affecting faecal contamination of water sources in the study area. It was common to see human and animal excreta littered around the environment in the study area. This is largely due to widespread open defecation by households and the free-range system of animal rearing. According to the 2010 PHC, $81.3 \%$ of households in Jirapa Municipality and 83.7\% of households in Kassena Nankana Municipal had no toilet facilities, and thus practised open defecation in the bush/field (GSS, 2014a, 2014b). Moreover, the few Kumasi Improved Pit Latrines (KVIP), Water Closets (WC) and pit latrines in the study area were reported to have poorly lined septic tanks, leading to seepage of faeces underground. Also, faecal waste was not treated in either Municipality and when toilet pits or tanks needed emptying, 
households often dumped faecal sludge in the open or abandoned their facility and constructed a new one. The presence of faeces in the environment was further exacerbated by open dumping of household waste; which often contain children's and animal faeces. Between the two study Municipalities, environmental sanitation practices in Jirapa Municipality were generally better than Kassena-Nankana Municipality. This further explains why more drinking water sources in Jirapa meet the WHO guideline, whereas a higher share of population is exposed to risk in Kassena-Nankana (see sections 4.2 and 4.3).

The third group of risk factors relate to poor compliance with guidelines on the siting and construction of drinking water infrastructure. The hydrogeologists of the CWSA argued that not every aquifer is suitable for the location of a water infrastructure. They stated that before a well is drilled, site feasibility studies, including risk assessment of hazardous events that may compromise water quality must be conducted. However, they noted that many boreholes, standpipes and protected wells had been constructed by private individuals, politicians and Non-Governmental Organisations (NGOs) without following due process. They intimated that where the CWSA is not involved in the construction of a water source, the site feasibility study is likely to be compromised. Consequently, some boreholes, standpipes and protected wells are poorly sited in swampy areas, close to surface water bodies and poorly lined pit toilets, exposing them to faecal contamination (Fig. 11 and 12). With regards to poor construction of water infrastructure, the CWSA hydrogeologists mentioned that some improved water sources, especially protected hand-dug wells, are very shallow, exposing them to faecal contamination through seepage of polluted water. From field observations, the depth of most protected hand-dug wells is about 10 metres which, according to the hydrogeologists interviewed, is too low to enable adequate filtration of polluted water seeping underground. This finding echoes previous studies that identified poor siting and construction of drinking 
water infrastructure as risk factors in faecal contamination of drinking water sources (Escamilla et al., 2013; Jewitt et al., 2018; Mkwate et al., 2016; Kirby et al., 2016).

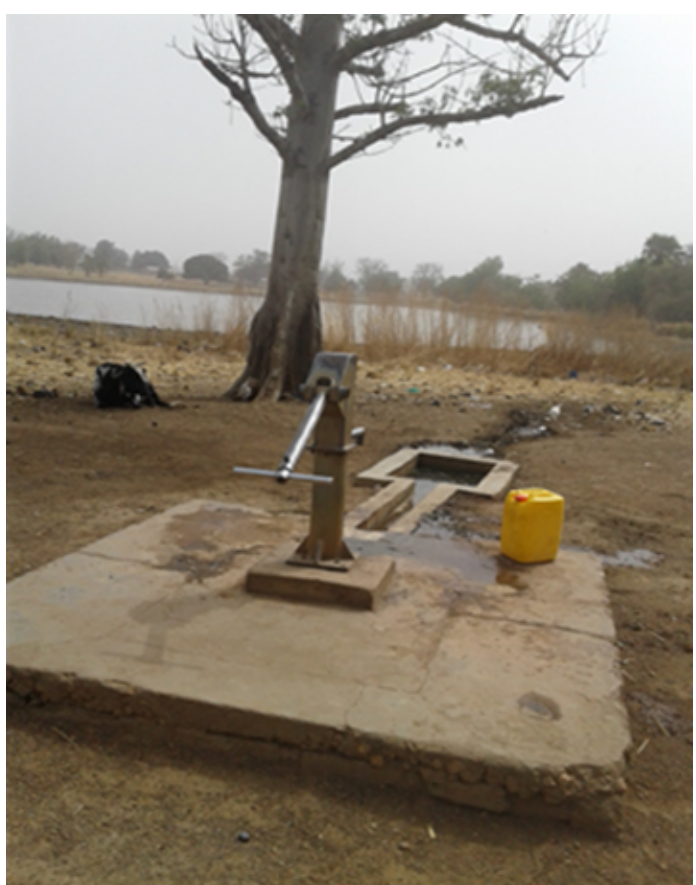

Source: Field survey, February 2018.

Fig. 11. Borehole sited close to a dam in Kologu, Kassena Nankana Municipality



Source: Field survey, December 2017

Fig. 12. Borehole sited close to a toilet in Piiyiri, Jirapa Municipality

Lastly, rainfall was identified as another important environmental exposure-related risks factor influencing faecal contamination of water sources; often in conjunction with other risk factors such as poor sanitation. According to the CWSA hydrogeologists, when it rains, faecal matter in the environment liquefies and seeps underground to pollute water. Some is also carried as runoff into surface water bodies, with the potential to pollute nearby improved water sources. This assertion is consistent with the findings of Kirby et al. (2016) in Rwanda who found a direct association between the risk of bacteriological contamination of water sources and continuous rainfall. The rain factor explains why faecal contamination of water sources is higher in the rainy season than in the dry season (see section 4.1). 


\section{Conclusions}

We found the risk assessment and risk management of water-related infectious diseases model presented in Fig. 1 very useful in assessing and explaining spatial and seasonal variations in faecal contamination of drinking water sources in the Jirapa and Kassena-Nankana Municipalities of Ghana through testing of faecal concentration in drinking water sources and assessment of local environmental conditions that can expose drinking water sources to contamination. From the results, faecal concentration in drinking water sources in the rainy season was significantly $(\mathrm{P}<0.05)$ higher than in the dry season. Consequently, the proportion of population at risk of faecal contamination in the rainy season $(41.5 \%)$ was 8.4 percentage points higher than in the dry season (33.1\%). This implies that in Ghana and LMICs as a whole, water surveillance agencies such as the United States Agency for International Development (USAID), UNICEF and WHO risk underestimating the proportion of people exposed to faecal contamination through drinking water in cross-sectional surveys. This study therefore recommends seasonal monitoring of populations at risk of faecal contamination in drinking water in regions characterised by significant climatic variability. However, for areas with limited resources, this study indicates that faecal contamination monitoring is most appropriate in the rainy season, when the risk of contamination is highest. Such an approach would help to provide more geographically relevant data that is useful for identifying fluctuations in quality and functionality of drinking water services along with associated health risks.

In contrast to the $\mathrm{WHO} / \mathrm{GSA}$ guideline that no drinking water source should contain $E$. coli/faecal coliforms, $27.3 \%$ and $51.8 \%$ of water samples in the dry and rainy seasons respectively contained faecal coliforms. Faecal coliforms were detected in all source types, including improved sources. About $26.2 \%$ of improved water samples in the dry season failed to comply with the guideline. In the rainy season, it increased to $48.5 \%$. This implies that improved water sources are not necessarily safe. This finding reinforces the call by the JMP on 
the need for monitoring faecal concentration in all drinking water sources in the SDG era. Noncompliance of drinking water sources, including improved water sources was linked to four main factors, comprising poor management of water infrastructure, poor sanitation practices and poor siting/construction of water infrastructure and rainfall. The presence of rain explains why faecal contamination in the wet season is significantly higher than in the dry season. To minimise the risk of faecal contamination of drinking water sources in the study areas and similar regions, we recommend safe environmental sanitation practices, effective management of drinking water sources and proper feasibility studies in the location of water infrastructure. Such approaches will be necessary in order to identify and address significant spatio-temporal variations in sustainable access to safely managed water and achieve SDG6's commitment to monitoring quality of service.

\section{Authors' contributions}

Alfred Dongzagla: Conceptualization, Methodology, Formal analysis, Writing- original draft, Writing- review \& editing. Sarah Jewitt: Supervision, Writing - review \& editing. Sarah O’Hara: Supervision, Writing - review \& editing.

\section{Declarations of competing interest}

The manuscript describes original work and is not under consideration by any other journal. The authors declare that they have no known competing financial interests or personal relationships that could have appeared to influence the work reported in this paper.

\section{Acknowledgements}

This paper draws on data from the lead author's doctoral research at the University of Nottingham, UK and we are very grateful to the Ghana Education Trust Fund (GETFund) for providing funding for this. We wish to also thank the University of Nottingham Graduate 
School for a small grant awarded the lead author in support of field data collection in Ghana. We would like to also express our deepest appreciation to Mr. Rockson Naalu Niminga, Director of Wa Municipal Physical Planning Department for providing us with spatial data for the study. Last but not the least, a special thanks to everyone who supported us with field data collection in Ghana. We wish to state that the funders had no involvement in the design and writing of this paper.

\section{References}

Adria Development, COFRAC ESSAIS, 3M, 2014. NF VALIDATION: Validation study according to the EN ISO 16140 standard. Retrieved from: https://nf-validation.afnor.org/wpcontent/uploads/2014/03/Synt-BIO-12-10-09-02_en.pdf. Date Accessed: 13/04/2017.

Agensi, A., Tibyangye, J., Tamale, A., Agwu, E., Amongi, C., 2019. Contamination Potentials of Household Water Handling and Storage Practices in Kirundo Subcounty, Kisoro District, Uganda. Journal of Environmental and Public Health, 2019, 8.

Agyekum, W. A., Dapaah-Siakwan, S., 2008. The Occurrence of groundwater in northeastern Ghana. In Adelana, S., MacDonald, A., (Eds.), Applied Groundwater Studies in Africa: IAH Selected Papers on Hydrogeology: Taylor and Francis.

Arnold, M., Van Derslice, J. A., Taylor, B., Benson, S., Allen, S., Johnson, M., . . Ansong, D., 2013. Drinking water quality and source reliability in rural Ashanti region, Ghana. Journal of Water Health, 11(1), 161-172.

Bain, R., Cronk, R., Hossain, R., Bonjour, S., Onda, K., Wright, J., . . Bartram, J., 2014. Global assessment of exposure to faecal contamination through drinking water based on a systematic review. Tropical Medice and International Health, 19(8), 917-927. 
Bakker, K., 2007. Trickle Down? Private sector participation and the pro-poor water supply debate in Jakarta, Indonesia. Geoforum, 38(5), 855-868.

Bartram, J., Fewtrell, L., \& Stenström, T., 2001. Harmonised assessment of risk and risk management for water-related infectious disease: an overview. In L. Fewtrell \& J. Bartram (Eds.), Water quality guidelines, standards and Health. WHO, IWA Publishing, Switzerland.

Boateng, D., Tia-Adjei, M., Adams, E. J., 2013. Determinants of Household Water Quality in the Tamale Metropolis, Ghana. Journal of Environment and Earth Science, 3(7).

Clasen, T. F., Bastable, A., 2003. Faecal contamination of drinking water during collection and household storage: the need to extend protection to the point of use. Journal of Water Health, 1(3), 109-115.

Creswell, J. W., Plano Clark, V. L., 2011. Designing and conducting mixed methods research. 2nd edition, Sage Publications, Los Angeles.

Creswell, J. W., 2007. An Introduction to Mixed Methods Research. Presentation, University of Nebraska-Lincoln. Retrieved from https://sbsrc.unl.edu/Introduction\%20to\%20Mixed\%20Methods.pdf, on 15/08/2018.

Escamilla, V., Knappett, P. S. K., Yunus, M., Streatfield, P. K., Emch, M., 2013. Influence of Latrine Proximity and Type on Tubewell Water Quality and Diarrheal Disease in Bangladesh. Annals of the Association of American Geographers, 103(2), 299-308.

Field, A., 2013. Discoverying Statitistics Using IBM SPSS Statistics (4th Eition ed.). London: SAGE Publications Ltd. 
Fonstad, M. A., 2013. Geographies of Water. Annals of the Association of American Geographers, 103(2), 251-252.

Ghana Standard Authority [GSA], 2019. GSA Standards Work Programme Bullet inJ anuary. Accra, Ghana. Retrieved from https://www.gsa.gov.gh/wpcontent/uploads/2019/12/GHANA-STANDARDS-AUTHORITY-WORK-PROGRAMME2019.pdf. Date Accessed: 01/04/2020.

Ghana Statistical Service [GSS], 2018. Snapshots on key Findings, Ghana Multiple Indicator Cluster Survey (MICS 2017/18), Survey Findings Report. Accra, Ghana.

GSS, 2013a. 2010 Population and housing census. Regional Analytic Report - Upper West Region, Accra, Ghana.

GSS, 2013b. 2010 Population and Housing Census. Regional Analytic Report - Upper East Region. Accra, Ghana.

GSS, 2014a. 2010 Population and Housing Census. District Analytic Report -Jirapa District.

GSS, 2014b. 2010 Population and Housing Census. District Analytic Report - KassenaNankana District. Accra, Ghana.

Ghana Statistical Service, Ghana Health Service, ICF International, 2015. Ghana Demographic Health Survey 2014. Maryland, USA. Retrieved from: https://dhsprogram.com/pubs/pdf/fr307/fr307.pdf. Date Accessed: 05/06/2017. 
GSS, 2011. GHANA Multiple Indicator Cluster Survey with an enhanced Malaria Module and Biomarker 2011. Final Report. Accra, Ghana. Retrieved from:

http://dhsprogram.com/pubs/pdf/FR262/FR262.pdf. Date Accessed: 07/01/2018.

Grady, C. A., Kipkorir, E. C., Nguyen, K., Blatchley, E. R., 2014. Microbial quality of improved drinking water sources: evidence from western Kenya and southern Vietnam. Journal of Water Health, 13(2), 607-612.

Jewitt, S., Mahanta, A., Gaur, K., 2018. Sanitation sustainability, seasonality and stacking: improved facilities for how long, where and whom? Geographical Journal, 184(3), 255-268.

Kirby, M. A., Nagel, C. L., Rosa, G., Iyakaremye, L., Zambrano, L. D., Clasen, T. F., 2016. Faecal contamination of household drinking water in Rwanda: A national cross-sectional study. Sci Total Environ, 571, 426-434.

Klasen, S., Lechtenfeld, T., Meier, K., Rieckmann, J., 2012. Benefits trickling away: the health impact of extending access to piped water and sanitation in urban Yemen. Journal of Development Effectiveness, 4(4), 537-565.

Kostyla, C., Bain, R., Cronk, R., Bartram, J., 2015. Seasonal variation of fecal contamination in drinking water sources in developing countries: A systematic review. Science of The Total Environment, 514, 333-343.

Kumpel, E., Peletz, R., Bonham, M., Khush, R., 2016. Assessing Drinking Water Quality and Water Safety Management in Sub-Saharan Africa Using Regulated Monitoring Data. Environmental Science and Technology, 50(20), 10869-10876. 
Lavanya, V., Ravichandran, S., 2013. Microbial contamination of drinking water at the source and household storage level in the peri-urban area of southern Chennai and its implication on health, India. Journal of Public Health, 21(5), 481-488.

McDonald, R., Douglas, I., Revenga, C., Hale, R., Grimm, N., Gronwall, J., Fekete, B., 2011. Global urban growth and the geography of water availability, quality, and delivery. Ambio, $40(5), 437-446$

Mkwate, R. C., Chidya, R. C. G., Wanda, E. M. M., 2016. Assessment of Drinking Water Quality and Rural HouseholdWater Treatment in Balaka District, Malawi. Physics and Chemistry of the Earth.

Odagiri, M., Schriewer, A., Daniels, M. E., Wuertz, S., Smith, W. A., Clasen, T., Schmidt, W., Jin, Y., Torondel, B., Misra, P. R., Panigrahi, P., Jenkins, M. W., 2016. Human fecal and pathogen exposure pathways in rural Indian villages and the effect of increased latrine coverage. Water Research,100, 232-244.

O'Hara, S., Hannan, T., Genina, M., 2008. Assessing access to safe water and monitoring progress on MDG7 target 10 (access to safe water and basic sanitation): Lessons from Kazakhstan. Water Policy, 10(1), 1-24

Onda, K., LoBuglio, J., Bartram, J., 2012. Global Access to Safe Water: Accounting for Water Quality and the Resulting Impact on MDG Progress. International Journal of Environmental Research and Public Health, 9(3), 880-894.

O'Reilly, K., Halvorson, S., Sultana, F., Laurie, N., 2009. Introduction: global perspectives on gender-water geographies. Gender, Place \& Culture, 16(4), 381-385. 
Pullan, R. L., Freeman, M. C., Gething, P. W., Brooker, S. J., 2014. Geographical inequalities in use of improved drinking water supply and sanitation across Sub-Saharan Africa: mapping and spatial analysis of cross-sectional survey data. PLoS Med, 11(4).

Schraft, H., \& Watterworth, L. A., 2005. Enumeration of heterotrophs, fecal coliforms and Escherichia coli in water: comparison of $3 \mathrm{M}^{\mathrm{TM}}$ Petrifilm ${ }^{\mathrm{TM}}$ plates with standard plating procedures. Journal of Microbiological Methods, 60(3), 335-342.

Schriewer, A., Odagiri, M., Wuertz, S., Misra, P. R., Panigrahi, P., Clasen, T., Jenkins, M. W., 2015. Human and Animal Fecal Contamination of Community Water Sources, Stored Drinking Water and Hands in Rural India Measured with Validated Microbial Source Tracking Assays. American Journal of Tropical Medicine and Hygiene, 93(3), 509-516.

Smiley, S. L., 2017. Quality matters: incorporating water quality into water access monitoring in rural Malawi. Water International, 42(5), 585-598.

Sultana, F., 2009. Fluid lives: subjectivities, gender and water in rural Bangladesh. Gender, Place \& Culture, 16(4), 427-444.

Sultana, F., 2011. Suffering for water, suffering from water: Emotional geographies of resource access, control and conflict. Geoforum, 42(2), 163-172.

Taro, Y., 1973. Statistics: An Introductory Analysis (Third Edition ed.). New York: Harper and Row Publishers Inc.

Taylor, D. J., Khush, R., Peletz, R., Kumpel, E., 2018. Efficacy of microbial sampling recommendations and practices in sub-Saharan Africa. Water Research,134, 115-125. 
Truelove, Y., 2011. (Re-)Conceptualizing water inequality in Delhi, India through a feminist political ecology framework. Geoforum, 42(2), 143-152

United Nations Children's Fund (UNICEF) and World Health Organization, 2018. Core questions on water, sanitation and hygienefor household surveys: 2018 update. New York. Retrieved from: https://washdata.org/sites/default/files/documents/reports/2019-03/JMP2018-core-questions-for-household-surveys.pdf. Date Accessed: 05/05/2019.

United Nations Children's Fund, World Health Organization, 2019. Progress on household drinking water, sanitation and hygiene 2000-2017, special focus on inequalities. New York. Retrieved from https://www.who.int/water_sanitation_health/publications/jmp-2019-fullreport.pdf. Date Accessed: 23/03/2019.

United Nations, 2015. Transforming Our World: The 2030 Agenda for Sustainable Development. A/RES/70/1. Retrieved from:

https://sustainabledevelopment.un.org/content/documents/21252030\%20Agenda $\% 20$ for $\% 20$ Sustainable\%20Development\%20web.pdf. Date Accessed: 29/10/2016.

Vail, J. H., Morgan, R., Merino, C. R., Gonzales, F., Miller, R., \& Ram, J. L., 2003. Enumeration of Waterborne Escherichia coli with Petrifilm Plates. Journal of Environmental Quality, 32(1), 368-373.

Wagah, G. G., Onyango, G. M., Kibwage, J. K., 2010. Accessibility of water services in Kisumu municipality, Kenya Journal of Geography and Regional Planning, 3(4), 114-125. WHO, 2019. Fact Sheet on Water. Retrieved from https://www.who.int/en/news-room/factsheets/detail/drinking-water . Date Accessed: 10/04/2020. 
WHO, 2011. Guidelines for Drinking-water Quality. Geneva. Retrieved from:

https://www.who.int/water sanitation health/publications/2011/dwq guidelines/en/. Date Accessed: 20/10/2016.

WHO/UNICEF Joint Monitoring Programme, 2006. Meeting the MDG Drinking Water and Sanitation Target. The Urban and Rural Challenge of the Decade. New York. Retrieved from: http://www.who.int/water sanitation health/monitoring/jmpfinal.pdf. Date Accessed: $25 / 10 / 2016$

WHO/UNICEF Joint Monitoring Programme, 2015. JMP Green Paper.: Global Monitoring of Water, Sanitation and Hygiene Post 2015. Retrieved from: http://www.wssinfo.org/fileadmin/user_upload/resources/JMP-Green-Paper-15-Oct-2015.pdf. Date Accessed: 15/10/2016. 